\title{
Biologically variable ventilation in patients with acute lung injury: a pilot study
}

\author{
Stephen Kowalski, MD • Michael C. McMullen, MD • \\ Linda G. Girling, BSc $\cdot$ Brendan G. McCarthy, MD
}

Received: 10 September 2012/ Accepted: 25 January 2013/Published online: 6 April 2013

(C) The Author(s) 2013. This article is published with open access at Springerlink.com

\section{To the Editor,}

Biologically variable ventilation (BVV) involves the delivery of a fixed minute ventilation but with a variable respiratory rate and a correspondingly variable tidal volume. This type of ventilation introduces a more physiological breathing pattern than traditional types of mechanical ventilation. It has been shown to improve oxygenation and ventilation in various animal models of lung injury when compared with conventional monotonous assist control ventilation (AC). ${ }^{1-3}$

We report our preliminary experience with $\mathrm{BVV}$ in eight critically ill patients. With BVV, the ventilator is configured so that the product of the respiratory rate and tidal volume is constant. The average coefficient of variation in the size of tidal volume was $30 \%$.

The local Research and Ethics Board of the University of Manitoba approved this study in February 2006, and informed consent was obtained from the patients' legal representatives. The eight patients in this study were intubated and ventilated for at least $72 \mathrm{hr}$ in the medical or surgical intensive care units at the Health Sciences Centre in Winnipeg. Their baseline ratio of partial pressure of arterial oxygen to the fraction of inspired oxygen $\left(\mathrm{PaO}_{2} /\right.$

S. Kowalski, MD $(\bowtie) \cdot$ L. G. Girling, BSc

Department of Medicine and Perioperative Medicine,

Health Sciences Centre, University of Manitoba,

Winnipeg, MB, Canada

e-mail: sekowalski@hsc.mb.ca

M. C. McMullen, MD

Department of Anesthesia, Queen's University,

Kingston, ON, Canada

B. G. McCarthy, MD

Department of Surgery, University of Manitoba,

Winnipeg, MB, Canada
$\mathrm{F}_{1} \mathrm{O}_{2}$ ) was $100-300 \mathrm{mmHg}$. The study was conducted as a crossover trial with patients acting as their own control. The patients were randomized to begin with either BVV or $\mathrm{AC}$, and their lungs were ventilated for a four-hour period in each mode of ventilation.

The baseline tidal volume was set at $6 \mathrm{~mL} \cdot \mathrm{kg}^{-1}$ to comply with the adult respiratory distress syndrome (ARDS) protocol. The patients were switched to a modified Esprit $^{\circledR}$ ventilator (Respironics, Carlsbad, CA, USA) that could be controlled by computer software. The computer ran a variability file that was recorded from a healthy individual and consisted of 1,489 breaths. Arterial blood gases, static lung compliance, and dead space $\left(\mathrm{V}_{\mathrm{D}} / \mathrm{V}_{\mathrm{T}}\right)$ were measured every hour. After completion of the study, the patients were returned to their baseline mode of ventilation. Continuous variables were compared using repeated measures one-way analysis of variance with post hoc least squares matrices to enable between group and within group comparisons. For within group comparisons, a Bonferroni correction for multiple comparisons was used.

None of the patients required an increase in $\mathrm{F}_{1} \mathrm{O}_{2}$ or change in the level of positive end-expiratory pressure during the study. There was improvement in the oxygen index $\left(\mathrm{F}_{1} \mathrm{O}_{2} \times\right.$ mean airway pressure $\left.\times 100 / \mathrm{PaO}_{2}\right)$ after four hours of BVV compared with $\mathrm{AC}(7.1 v s 11.5 \mathrm{~cm}$ $\mathrm{H}_{2} \mathrm{O} \cdot \mathrm{mmHg}^{-1}$, respectively; $P=0.034$ ) (Figure). There was no statistically significant change in arterial $\mathrm{PaCO}_{2}$ after four hours of BVV. The $\mathrm{V}_{\mathrm{D}} / \mathrm{V}_{\mathrm{T}}$ ratio decreased after four hours of BVV compared with AC (0.64 vs 0.68 , respectively; $P=0.017$ ) and lung compliance improved $\left(0.36\right.$ vs $0.34 \mathrm{~mL} \cdot \mathrm{cm} \quad \mathrm{H}_{2} \mathrm{O}^{-1} \cdot \mathrm{kg}^{-1}$, respectively; $P=0.049)$.

A series of mechanisms have been proposed to account for the improved ventilation with BVV in the setting of ARDS. A presumed mechanism is thought to be enhanced 


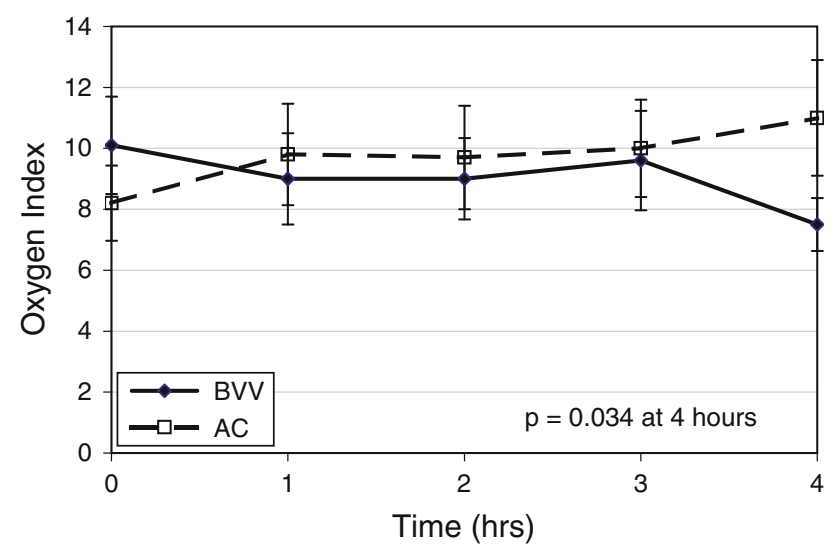

Figure Oxygen index $v s$ time. The oxygen index $\left(\mathrm{F}_{\mathrm{I}} \mathrm{O}_{2} \times\right.$ mean airway pressure $\times 100 / \mathrm{PaO}_{2}$, expressed in $\mathrm{cm} \mathrm{H}_{2} \mathrm{O} \cdot \mathrm{mmHg}^{-1}$ ) in patients ventilated with biologically variable ventilation (BVV) compared with assist control ventilation (AC). At four hours, there was an improved oxygen index with BVV compared with AC (7.1 vs $11.5 \mathrm{~cm} \mathrm{H}_{2} \mathrm{O} \cdot \mathrm{mmHg}^{-1}$, respectively; $P=0.034$ )

alveolar recruitment. Evidence for alveolar recruitment with BVV has been shown by computed tomography scanning in a porcine model of ARDS. ${ }^{3}$ If alveoli can be recruited and kept open, improved gas exchange and lung compliance would be expected with BVV. By using a variety of tidal volumes and respiratory rates, the probability of selecting the appropriate time constant for a given subpopulation of alveolar units is greatly increased. Recent editorials advocate for the role of "noisy" or physiological variability to aid ventilation of patients. ${ }^{4,5}$ This pilot project suggests that BVV may warrant further study as a mode of ventilation in patients who require controlled ventilation.

Competing interests None declared.

Open Access This article is distributed under the terms of the Creative Commons Attribution Noncommercial License which permits any noncommercial use, distribution, and reproduction in any medium, provided the original author(s) and the source are credited. The exclusive right to any commercial use of the article is with Springer.

\section{References}

1. Lefevre GR, Kowalski SE, Girling LG, Thiessen DB, Mutch WA. Improved arterial oxygenation after oleic acid lung injury in the pig using a computer-controlled mechanical ventilator. Am J Respir Crit Care Med 1996; 154: 1567-72.

2. Mutch WA, Harms S, Graham MR, Kowalski SE, Girling LG, Lefevre GR. Biologically variable or naturally noisy mechanical ventilation recruits atelectatic lung. Am J Respir Crit Care Med 2000; 162: 319-23.

3. Graham MR, Gulati H, Kha L, Girling LG, Goertzen A, Mutch WA. Resolution of pulmonary edema with variable mechanical ventilation in a porcine model of acute lung injury. Can J Anesth 2011; 58: 740-50.

4. Shimabukuro DW, Gropper MA. Noisy mechanical ventilation: listen to the melody. Anesthesiology 2009; 110: 214-5.

5. Allardet-Servent $J$. Adding noise to mechanical ventilation: so obvious! Crit Care Med 2012; 40: 2725-6. 